\title{
Eastern Cooperative Oncology Group
}

National Cancer Institute

\section{Source}

National Cancer Institute. Eastern Cooperative Oncology Group. NCI Thesaurus. Code C25491.

A cooperative group funded primarily by the $\mathrm{NCl}$, one of the largest clinical cancer research organizations in the US, incorporating universities, medical centers, Community Clinical Oncology Programs, and Cooperative Group Outreach Programs with almost 6000 physicians, nurses, pharmacists, statisticians, and clinical research associates from the US, Canada, and South Africa. ECOG has more than 90 active clinical trials in all types of adult malignancies. Annual accrual is 6,000 patients, with more than 20,000 patients in follow-up. 